\title{
Kahramanmaraş’ta Bağcıllğın Mevcut Durumu, Potansiyeli ve Geliştirilmesi
}

\author{
İsmail GÜVENÇ \\ Kahramanmaraş Sütçü İmam Üniversitesi, Ziraat Fakültesi, Bahçe Bitkileri Bölümü, Kahramanmaraş \\ ${ }^{1}$ https://orcid.org/ 0000-0002-4686-9487 \\ 凹: guvencis46@gmail.com
}

\section{ÖZET}

Türkiye'de üzüm üretimi 4.0 milyon ton kadardır. Kahramanmaraş 80-90 bin ton üzüm üretim miktarı ile Türkiye'de üzüm üretiminde \% 2.01'lik paya sahiptir. Türkiye'nin bağ alanları içinde Kahramanmaraş'ta bağcılık yapılan alanlarının payı \% 3.75'dir. Türkiye ve Kahramanmaraş’ın bağ alanları $(r=0,318)$ ve üzüm üretimi $(r=0,367)$ arasında pozitif bir ilişki vardır. Kahramanmaraş'ta üretilen üzümün çekirdekli olarak \% 74.08'ini sofralık ve \% 25.50'ini ise kurutmalık- üzüm çeşitleri oluşturmaktadır. Kahramanmaraş’ın vejetasyon süresi 280 gün kadar olup bu süre bağcılık için yeterlidir. Kahramanmaraş yıllık ortalama $16.9{ }^{\circ} \mathrm{C}$ civarında bir sıcaklığa sahip olup bu ortalama sicaklık değerine göre ilin iklimi birçok üzüm çeşidinin yetiştiriciliğine uygundur. Herhangi bir yerde bağcilık yapılabilmesi için gerekli olan asgari etkili sıcaklık toplamı (EST) 900 gün-derece olup Kahramanmaraş için EST değeri 2.895 gün-derece olarak tespit edilmiştir. Öte yandan İlin güneşlenme süresi 2.144 saat olduğundan bağcılık için uygundur. Kahramanmaraş'ta yıllık ortalama yağış ve vejetasyon dönemindeki ortalama yağış miktarı sirasıyla 724.7 ve mm 359.6 mm'dir. Bu nedenle İldeki bağlar yetiştirme döneminde ihtiyaç durumu dikkate alınarak sulanmalıdır. Sonuç olarak İlin mevcut bağcılık durumu ve potansiyeli dikkate alındığında Kahramanmaraş'ta bağcılığın daha da geliştirilmesi mümkündür.
Araştırma Makalesi

$\begin{array}{ll}\text { Makale Tarihçesi } \\ \text { Geliş Tarihi } & : 23.08 .2019 \\ \text { Kabul Tarihi } & : 14.01 .2020\end{array}$

Anahtar Kelimeler

Kahramanmaraş

Üzüm üretimi

Bağ alanı

Bağcılık

\section{Current Situation, Potential and Development of Viticulture in Kahramanmaras}

\section{ABSTRACT}

Turkey's grape production is estimated to be 4.0 million tonnes. Kahramanmaras has $2.01 \%$ share of Turkey with $80-90$ thousand tons production and covers $3.75 \%$ of the vineyard area of Turkey. There is a positive correlation between vineyard areas $(r=0.318)$ or grape production $(r=0.367)$ of Turkey and Kahramanmaras. The grape production of Kahramanmaras consisted of table grapes (74.08\%) and raisin $(25.50 \%)$. The vegetation period of Kahramanmaras is 280 days and it is sufficient for viticulture. Kahramanmaras has an average annual temperature of $16.9{ }^{\circ} \mathrm{C}$, which provide a suitable climate for the cultivation of many grape varieties. The effective temperature sum required for viticulture was determined as 2.895 day-degree. The sunshine duration for viticulture growing at any place is required to be 1300 hours during the vegetation period. Kahramanmaras is suitable for viticulture growing considering that the sunshine duration of the province is 2.144 hours in the vegetation period. The rainfall of annual average and vegetation period was respectively $724.7 \mathrm{~mm}$ and $359.6 \mathrm{~mm}$. Vineyards be irrigated as needed including in low rain time periods or in summers. As a result, it is possible to develop more viniculture in Kahramanmaras by considering the current situation and potential of viticulture in the province.

\section{Research Article}

$\begin{array}{ll}\text { Article History } & \\ \text { Received } & : 23.08 .2019 \\ \text { Accepted } & : 14.01 .2020\end{array}$

\section{Keywords}

Kahramanmaras

Grape production

Vineyard

Viticulture

To Cite : Güvenç İ 2020. Kahramanmaraş’ta Bağcılığın Mevcut Durumu, Potansiyeli ve Geliştirilmesi. KSÜ Tarım ve Doğa Derg 23 (3): 554-560. DOI: 10.18016/ksutarimdoga.vi.610041 


\section{GİRIŞ̧}

Kahramanmaraş’ta bağcılığın tarihçesi oldukça eski dönemlere kadar gitmektedir. Nitekim Kahramanmaraş Arkeoloji Müzesinde asmanın da yer aldığg birçok tarihi eser sergilenmektedir: Örneğin, MÖ. 900-800 yüzyıla ait elinde üzüm salkımı tutan bir erkek heykeli ile MS. 1-2. yüzyıla ait taban mozaiklerinde asma yaprak ve üzüm motifleri mevcuttur. Osmanlı Devleti'nde Maraş Tahrir Defteri'nde (MS 1563) günümüzde Kahramanmaraş’ın yer aldığı bu yörede asma kültürünün yaygın olduğu, ilin kuzeyde kesimlerine doğru, dağlık kısımlarda ve Elbistan tarafindan azaldığı belirtilmiştir (Yinanç ve Elibüyük, 1988). Daha yakın zamandaki kaynaklarda da Kahramanmaraş'ta bağcılı̆̆ın tarihçesinin eski olduğu bildirilmiştir. Nitekim Oraman; 1950'li yıllarda yayımı yapılan kitabında "Maraş Akdeniz mıntıkasının en önemli üç üzümcü ilidir" bilgisine yer vermektedir (Oraman 1970, 1972). Ayrica yazar tarafindan yörede Mahrabaşı ve Kabarcık gibi üzüm çeşitlerinin yaygın yetiştirildiği de belirtilmiştir. Bu çeşitler günümüzde de bu ilde yaşayanlar tarafindan sofralık veya şıralık olarak tüketilmektedir. Ayrıca, Kahramanmaraş'ta üretimi en fazla yapılan meyve türünün üzüm olduğu ve bağcilığın bu yörede gelişme potansiyelinin olduğu belirtilmiştir (Sütyemez ve Gündeşli, 2004)

Son yıllarda Türkiye bağ alanları 4.17 milyon da, üzüm üretimi ise 4.0-4.2 milyon ton kadardır. Üzüm üretimi bakımında dünya ülkeleri arasında Türkiye 5’inci sıradadır (Karabat, 2018). Türkiye'nin üzüm üretiminin yıllara göre az çok farklılık göstermekle birlikte \%34.31'i sofralık-çekirdekli, \%15.90'ı sofralık-çekirdeksiz, \%11.62'i şaraplık, \%8.64'ü kurutmalık-çekirdekli ve \% 29,52'ini kurutmalık-çekirdeksiz üzümden oluşmaktadır (Anonim, 2019a).

Ülkemizde bağcılığın önemli olduğu illerden biri de Kahramanmaraş'tır. $\mathrm{Bu}$ ilimizin bağcılıkta potansiyelini ve geliştirme imkanının var olup olmadığını ortaya konulması gerekir. Ülkemizde bağcılık üzerine yazılan eserlerde bazı iller için özel bilgilere yer verilmiş olmakla birlikte (Oraman 1970, 1972); Kahramanmaraş'ın bağcılık için iklim durumu yeterince irdelenmemiştir. Aynı şekilde sonraki yıllarda yazılan kaynaklarda da bu bilgiler bulunmamaktadır (Yıldırım ark., 2005; Uzun, 2015). Bunların yanında Kahramanmaraş bağcılığı yeterince incelenmemiştir.

Kahramanmaraş bağcılığında yerel pazarlara yönelik ve Mahrabaşı, Kabarcık ve Peygamber Üzümü gibi belirli çeşitlerin üretimine yer verilmektedir. Bunun yanında bağların dağlık ve kurak arazilerde tesis edilmesi, yetiştirme tekniklerindeki noksanlıklar, düşük girdi kullanımı önemli sorunlar arasındadır (Sabancı, 2009). Buna göre standart üzüm çeşitleri ile yeni bağların kurulması ve modern bağcılığın yaygınlaştırılması gereklidir. Bu amaçla İlin mevcut durumu ve potansiyelini ortaya koyan sinırlı sayıda çalışma bulunduğundan; bu çalışmada Kahramanmaraş'ta bağcılığın tarihçesi, mevcut durumu ve potansiyeli ve geliştirme imkanları incelenmiştir.

\section{MATERYAL ve METOT}

Bu çalışmada, Türkiye İstatistik Kurumu'na (Anonim 2019a); Meteroloji İşleri Genel Müdürlüğü’ne (Anonim, 2019b) ve Tarım ve Orman Bakanlığı Bitkisel Üretim Genel Müdürlüğü'ne (BÜGEM) (Anonim,2 013; Anonim, 2019c ) ait bitkisel üretim ve iklim verilerinden yararlanılmıştır.

Bir yörede ilkbaharın son ve sonbaharın ilk donları arasında kalan süre vejetasyon süresi olarak kabul edilmektedir. Kahramanmaraş merkezde ortalama olarak ilkbaharin son donları 01-10 Mart ve Sonbaharın ilk donları ise 11-22 Aralık tarihinde gözlenmektedir (Güvenç, 2017; Anonim 2019b). Bu vejetasyon dönemindeki toplam güneşlenme süresi ve toplam yağış miktarı etkili sıcaklık toplamı değerleri (EST) Kahramanmaraş'a ait güneşlenme süresi, yağış ve ortalama sicaklık gibi meteorolojik verilerden (ikincil) yararlanarak hesaplanmıştır. Etkili sıcaklık toplamı (EST) tomurcukların kabarmaya başladığı tarih ile üzümlerin olgunlaşma tarihi arasındaki dönemde $10^{\circ} \mathrm{oC}$ 'nin üzerindeki günlük ortalama sicaklıkların toplanması ile elde edilen değerdir (Yıldırım ve ark., 2005; Uzun, 2015).

Yukarda belirtilen kurum kayitlarından elde edilen verilerden ihtiyaç duyulan hesaplamalar [Korelasyon (r), (\%), Değişim Katsayısı (DK)] Microsoft Excel programıyla yapılmıştır. Bağımlı değişkendeki değişimin ne kadarının bağımsız değişkence açıklanabileceğini gösteren 'Belirlilik Katsayısı' (BK); korelasyon katsayısının karesi alınarak hesaplanmıştır. Ayrıca kullanılan istatistik serilerindeki değişkenlik değişim katsayısı (DK)ile belirlenmiştir (Yüzer ve ark., 2006).

\section{BULGULAR ve TARTIŞMA}

Kahramanmaraş'ta bağcılığın mevcut durumu üretim miktarı ve alanı ile verimlilik durumu dikkate alınarak incelenmiştir.

\section{Üretim}

Ülkemizde üzüm üretimi 2004 yılında 3.5 milyon ton iken 2018 yılında 400 bin ton kadar artarak 3.9 milyon ton olarak gerçekleşmiştir. Türkiye üzüm üretiminin $\% 37.8$ 'i sofralık-çekirdekli, \% 11.65'i kurutmalıkçekirdeksiz, $\% \quad 11.79$ 'u şaraplık ve \% 39.25 'i kurutmalık üzüm üretiminden oluşmaktadır (Çizelge $1)$. 
Çizelge 1. 2004-2018 döneminde Türkiye'de toplam üzüm üretimi (ton).

Table 1. Grape production for Turkey in 2004- 2018 (tone).

\begin{tabular}{|l|l|c|c|c|c|c|}
\hline $\begin{array}{l}\text { Ylllar } \\
\text { Years }\end{array}$ & $\begin{array}{l}\text { Sofralık- } \\
\text { Cekirdekli } \\
\text { Table grapes } \\
\text { with seeds }\end{array}$ & $\begin{array}{l}\text { Sofralık- } \\
\text { Cekirdeksiz } \\
\text { Table grapes } \\
\text { without seeds }\end{array}$ & $\begin{array}{l}\text { Saraplık } \\
\text { Uzümler } \\
\text { Wine grape }\end{array}$ & $\begin{array}{l}\text { Kurutmalık- } \\
\text { Cekirdekli } \\
\text { Raisin with seeds }\end{array}$ & $\begin{array}{l}\text { Kurutmalık- } \\
\text { Cekirdeksiz } \\
\text { Raisin without } \\
\text { seeds }\end{array}$ & $\begin{array}{l}\text { Toplam** }^{* *} \\
\text { Total }^{*}\end{array}$ \\
\hline 2004 & 1.500 .000 & 400.000 & 370.000 & 350.000 & 880.000 & 3.500 .000 \\
\hline 2005 & 1.600 .000 & 400.000 & 450.000 & 400.000 & 1.000 .000 & 3.850 .000 \\
\hline 2006 & 1.564 .009 & 496.158 & 444.199 & 370.764 & 1.124 .933 & 4.000 .063 \\
\hline 2007 & 1.487 .602 & 424.937 & 482.292 & 335.010 & 882.940 & 3.612 .781 \\
\hline 2008 & 1.490 .185 & 480.501 & 470.285 & 321.142 & 1.156 .329 & 3.918 .442 \\
\hline 2009 & 1.695 .307 & 561.538 & 475.888 & 402.094 & 1.129 .893 & 4.264 .720 \\
\hline 2010 & 1.695 .727 & 553.803 & 461.508 & 431.326 & 1.112 .636 & 4.255 .000 \\
\hline 2011 & 1.696 .811 & 572.156 & 465.320 & 435.756 & 1.126 .308 & 4.296 .351 \\
\hline 2012 & 1.619 .849 & 599.964 & 400.659 & 417.521 & 1.196 .312 & 4.234 .305 \\
\hline 2013 & 1.634 .596 & 498.006 & 45.5229 & 466.529 & 957.049 & 4.011 .409 \\
\hline 2014 & 1.580 .585 & 586.164 & 445.127 & 427.533 & 1.135 .947 & 4.175 .356 \\
\hline 2015 & 1.305 .491 & 586.419 & 423.527 & 379.263 & 955.300 & 3.650 .000 \\
\hline 2016 & 1.380 .120 & 610.484 & 472.534 & 395.732 & 1.141 .130 & 4.000 .000 \\
\hline 2017 & 1.441 .000 & 668.000 & 488.000 & 363.000 & 1.240 .000 & 4.200 .000 \\
\hline 2018 & 1.487 .201 & 458.061 & 463.647 & 477.746 & 1.046 .345 & 3.933 .000 \\
\hline$(\%)^{*}$ & 37.81 & 11.65 & 11.79 & 12.65 & 26.60 & 100.00 \\
\hline
\end{tabular}

Kaynak: Anonim 2019a,c (TUIK) veri tabanından yararlanarak hazırlanmıştır.

*: 2018 yılında oransal dağılımı göstermektedir. **: $\mathrm{DK}=\% 6.08$.

Türkiye üzüm üretiminde Kahramanmaraş'ın payı \%2.01 olup son yıllarda 80-85 bin ton kadardır. Kahramanmaraş üzüm üretiminde miktar olarak önemli üretici iller arasında 9. sırada yer almaktadır. Kahramanmaraş ili Türkiye'de çekirdekli sofralık ve kurutmalık üzüm üretimi ile ön plandadır. Nitekim bu üzüm gruplarında il payının sofralıkta $\% 4.0$ ve kurutmalıkta \%6.0 olduğu belirlenmiştir (Çizelge 2).

Kahramanmaraş'ta üretilen toplam üzümün \%74.08'ini sofralık (çekirdekli) ve \%25.50'ini kurutmalık (çekirdekli) üzümler meydana getirmekte olup il çekirdekli sofralık ve kuru üzüm üretiminde önemli bir merkezdir (Çizelge 2).

2004-2018 yılları arasında Kahramanmaraş ili üzüm üretim miktarları Çizelge 3’te verilmiştir. İlin üzüm üretiminde 2015 yılına kadar bir artışın olduğu bu yıldan sonra bir azalma olduğu tespit edilmiştir.

İldeki toplam üzüm üretimi ile Türkiye'ninki arasında düşük düzeyde bir ilişkinin $(\mathrm{r}=0.367)$ olduğu belirlenmiştir. Kahramanmaraş ve Türkiye üretimi arasında \% 13.5 oranında bir etkileşim [belirlilik katsayısı $\left(\mathrm{r}^{2}\right)=0.135$ ] vardır.

\section{Bağcılık Yapılan Alan}

Türkiye ve Kahramanmaraş'ta bağcılık yapılan alanlardaki değişim Çizelge 4'de sunulmuştur. İlin bağ alanlarının Türkiye bağ alanları içindeki payı \%3.50 civarındadır. Gerek ülkemizde ve gerekse ilde bağ alanları incelenen 2004-2018 döneminde azalan bir seyir izlemektedir. Kahramanmaraş'ta 2004'de 269 bin da olan bağ yapılan alan \%43 azalarak 2018'de 149 bin dekara düşmüştür. Öte yandan Kahramanmaraş'ta bağ alanları Merkez ve Pazarcık ilçesinde yoğunlaşmış durumdadır. Pazarcık ilçesi bağ alanları çekirdekli-kurutmalık çeşitler bakımından önemdir.

Türkiye ve Kahramanmaraş'ta toplam bağ alanları arasındaki ilişki incelendiğinde orta düzeyde bir ilişkinin $(r=0.318)$ varlığından söz etmek mümkündür. Kahramanmaraş ve Türkiye üretimi arasında \%10.1 oranında bir etkileşim [belirlilik katsayısı $\left.\left(\mathrm{r}^{2}\right)=0.101\right]$ vardir.

\section{Verim}

Kahramanmaraş'ta önemli üretimi olan sofrallkçekirdekli ve kurutmalık-çekirdekli üzümlerde verim incelenmiştir (Çizelge 5). İlde bağların veriminin yıllara göre değişken olduğu görülmektedir. Bu durum ekolojik ve ekonomik şartların üzüm üretimi üzerine çok etkili olduğunu göstermesi bakımından önemlidir.

\section{Bağcılık Bakımından Kahramanmaraş'ın İklimi}

Bir yerde bağcılık yapılmak istendiğinde o yerin vejetasyon süresi, etkili sıcaklık toplamı, güneşlenme süresi ve yağış gibi iklim özelliklerinin öncelikle dikkate alınması gerekir. $\mathrm{Bu}$ nedenle Kahramanmaraş'ın bağcılık potansiyelini ortaya koyabilmek için bu özellikler incelenmiştir. 
Çizelge 2. Türkiye'de toplam üzüm üretimi ve önemli payı olan iller (ton).

Table 2. Production and major producer provinces of grape for Turkey in 2004-2018 (tone).

\begin{tabular}{|c|c|c|c|c|c|c|c|}
\hline $\begin{array}{l}\text { İller } \\
\text { Province }\end{array}$ & $\begin{array}{c}\text { Sofralık- } \\
\text { Çekirdekli } \\
\text { Table } \\
\text { grapes } \\
\text { with seeds }\end{array}$ & $\begin{array}{c}\text { Sofralık- } \\
\text { Çekirdeksiz } \\
\text { Table grapes } \\
\text { without seeds }\end{array}$ & $\begin{array}{l}\text { Şaraplik } \\
\text { Üzümler } \\
\text { Wine } \\
\text { grape }\end{array}$ & $\begin{array}{l}\text { Kurutmalık- } \\
\text { Çekirdekli } \\
\text { Raisin } \\
\text { with seeds }\end{array}$ & $\begin{array}{c}\text { Kurutmalık- } \\
\text { Çekirdeksiz } \\
\text { Raisin } \\
\text { without } \\
\text { seeds }\end{array}$ & $\begin{array}{c}\text { Toplam } \\
\text { Total }\end{array}$ & $\begin{array}{c}\text { Pay (\%) } \\
\text { Percentage }\end{array}$ \\
\hline Manisa & 57.394 & 385.741 & 6.830 & 744 & 1.083 .710 & 1.534 .419 & 36.53 \\
\hline Denizli & 67.250 & 205.788 & 94.555 & 27.789 & 77.092 & 472.474 & 11.25 \\
\hline Mersin & 256.895 & 14.792 & 16.226 & 16.315 & - & 304.228 & 7.24 \\
\hline İzmir & 29.183 & 40.826 & 25.605 & 900 & 77.119 & 173.633 & 4.13 \\
\hline Mardin & 63.705 & - & 31.858 & 63.032 & - & 158.595 & 3.78 \\
\hline Diyarbakır & 88.680 & 185 & 16.787 & 23.601 & - & 129.253 & 3.08 \\
\hline Gaziantep & 81.494 & 6.362 & 6.376 & 31.407 & - & 125.639 & 2.99 \\
\hline Nevşehir & 33.142 & - & 5.2458 & 28.006 & - & 113.606 & 2.70 \\
\hline Kahramanmaraş & 62.649 & 357 & - & 21.564 & - & 84.570 & 2.01 \\
\hline Kilis & 1.797 & - & 67.051 & 15.685 & - & 84.533 & 2.01 \\
\hline Sakarya & 77.136 & - & - & - & - & 77.136 & 1.84 \\
\hline Adıyaman & 54589 & 168 & 58 & 21.977 & - & 76.792 & 1.83 \\
\hline Konya & 34516 & 60 & 1293 & 34.728 & 1 & 70.598 & 1.68 \\
\hline Hatay & 53953 & 2097 & 6.973 & - & - & 63.023 & 1.50 \\
\hline Isparta & 30637 & - & 1.344 & 24.211 & - & 56.192 & 1.34 \\
\hline Elazığ & 36816 & - & 19.047 & - & - & 55.863 & 1.33 \\
\hline Tokat & 8012 & - & 38.166 & - & - & 46.178 & 1.10 \\
\hline Tekirdağ & 15743 & - & 29.556 & - & & 45.299 & 1.08 \\
\hline Toplam (18 İl) & 1.053 .591 & 656.376 & 414.183 & 309.959 & 1.237 .922 & 3.672 .031 & 87.42 \\
\hline Türkiye Toplamı & 1.441 .000 & 668.000 & 488.000 & 363.000 & 1.240 .000 & 4.200 .000 & 100,00 \\
\hline $\begin{array}{l}\text { Kahramanmaraş/ } \\
\text { Türkiye }^{(1)}\end{array}$ & 4,00 & - & - & 6,00 & - & & 2.01 \\
\hline $\begin{array}{l}\text { Kahramanmaraş } \\
\text { (\%) (2) }\end{array}$ & 74.08 & 0.42 & & 25.50 & - & 84.570 & 100.00 \\
\hline
\end{tabular}

Kaynak: TUIKK veri tabanından yararlanarak hazırlanmıştır (Anonim, 2019a).

(1): Kahramanmaraş'ın Türkiye üretiminde payı.

(2): Kahramanmaraş'ta önemli üzüm gruplarının oransal dağılımı.

Çizelge 3. 2004-2018 döneminde Kahramanmaraş’ta üzüm üretimi (ton/yıl).

Table 3. Grape production for Kahramanmaras in 2004- 2018 (tone/year).

\begin{tabular}{|c|c|c|c|c|c|}
\hline $\begin{array}{l}\text { İller } \\
\text { Province }\end{array}$ & $\begin{array}{l}\text { Sofralık-Çekirdekli } \\
\text { Table grapes with } \\
\text { seeds }\end{array}$ & $\begin{array}{l}\text { Sofralık-Çekirdeksiz } \\
\text { Table grapes without } \\
\text { seeds }\end{array}$ & $\begin{array}{c}\text { Şaraplık Üzümler } \\
\text { Wine grape }\end{array}$ & $\begin{array}{c}\text { Kurutmalık- } \\
\text { Çekirdekli } \\
\text { Raisin with seeds }\end{array}$ & $\begin{array}{c}\text { Toplam } \\
\text { Total }\end{array}$ \\
\hline 2004 & 89.520 & 0 & 510 & 25.360 & 115.390 \\
\hline 2005 & 104.220 & 0 & 510 & 28.485 & 133.215 \\
\hline 2006 & 90.095 & 0 & 200 & 29.985 & 120.280 \\
\hline 2007 & 69.053 & 0 & 1.600 & 6.210 & 76.863 \\
\hline 2008 & 146.116 & 0 & 1.776 & 55.120 & 203.012 \\
\hline 2009 & 164.908 & 0 & 3.100 & 80.550 & 248.558 \\
\hline 2010 & 209.039 & 0 & 3.098 & 51.100 & 263.237 \\
\hline 2011 & 194.714 & 0 & 0 & 55.525 & 250.239 \\
\hline 2012 & 200.804 & 0 & 0 & 55.475 & 256.279 \\
\hline 2013 & 152.999 & 0 & 0 & 62.250 & 215.249 \\
\hline 2014 & 149.549 & 0 & 0 & 61.035 & 210.584 \\
\hline 2015 & 199.462 & 0 & 0 & 72.315 & 271.777 \\
\hline 2016 & 47.817 & 896 & 0 & 14.015 & 62.728 \\
\hline 2017 & 62.649 & 357 & 0 & 21.564 & 84.570 \\
\hline 2018 & 52.151 & 683 & 0 & 19.555 & 72.389 \\
\hline
\end{tabular}

Kaynak: TUIKK veri tabanından yararlanarak hazırlanmıştır (Anonim, 2019a). Türkiye ve Kahramanmaraş üzüm üretimi arasındaki Korelasyon katsayısı $r=0,367$ ve $\mathrm{BK}\left(\mathrm{r}^{2}\right)=0.135(\% 13,50)$. Kahramanmaraş üzüm üretimi için $\mathrm{DK}=\% 42,87$. 
Çizelge 4. 2004-2018 döneminde bağcılık yapılan alan ve Kahramanmaraş'ın payı.

Table 4. Grape area and ratio for Kahramanmaras in 2004- 2018.

\begin{tabular}{|l|c|c|c|c|c|}
\hline & \multicolumn{2}{|c|}{$\begin{array}{c}\text { Kahramanmaraş } \\
\text { Kahramanmaras }\end{array}$} & \multicolumn{2}{c|}{$\begin{array}{c}\text { Türkiye } \\
\text { Turkey }\end{array}$} & $\begin{array}{c}\text { Türkiye'de } \\
\text { Kahramanmaraş'ın Payı } \\
\text { (\%) }\end{array}$ \\
\cline { 1 - 4 } $\begin{array}{l}\text { Yıllar } \\
\text { Years }\end{array}$ & $\begin{array}{l}\text { Alan (da) } \\
\text { Area (da) }\end{array}$ & $\begin{array}{l}\text { Değişim (\%) } \\
\text { Changing (\%) }\end{array}$ & $\begin{array}{l}\text { Alan (da) } \\
\text { Area (da) }\end{array}$ & $\begin{array}{l}\text { Değişim (\%) } \\
\text { Changing (\%) }\end{array}$ & $\begin{array}{c}\text { Ratio of Kahramanmaras } \\
\text { in Turkey (\%) }\end{array}$ \\
\hline 2004 & 269.520 & 100.00 & 5.250 .000 & 100.00 & 5.13 \\
\hline 2005 & 274.990 & 10.00 & 5.196 .000 & 98.97 & 5.29 \\
\hline 2006 & 249.620 & 92.60 & 5.156 .728 & 98.22 & 4.84 \\
\hline 2007 & 252.483 & 93.70 & 4.833 .705 & 92.07 & 5.22 \\
\hline 2008 & 262.583 & 97.40 & 4.716 .019 & 89.83 & 5.57 \\
\hline 2009 & 281.238 & 104.30 & 4.702 .781 & 89.58 & 5.98 \\
\hline 2010 & 283.838 & 105.30 & 4.727 .754 & 90.05 & 6.00 \\
\hline 2011 & 336.324 & 124.80 & 4.674 .043 & 89.03 & 7.20 \\
\hline 2012 & 334.193 & 124.00 & 4.606 .008 & 87.73 & 7.26 \\
\hline 2013 & 332.673 & 123.40 & 4.620 .313 & 88.01 & 7.20 \\
\hline 2014 & 333.340 & 123.70 & 4.611 .554 & 87.84 & 7.28 \\
\hline 2015 & 333.290 & 123.70 & 4.576 .340 & 87.17 & 3.75 \\
\hline 2016 & 160.626 & 59.60 & 4.282 .840 & 81.58 & 3.75 \\
\hline 2017 & 153.500 & 57.00 & 4.090 .320 & 77.91 & 3.58 \\
\hline 2018 & 149.615 & 55.40 & 4.170 .410 & 79.42 & \\
\hline
\end{tabular}

Kaynak: Anonim 2019a,c (TUIK) verilerinden yararlanarak hazırlanmıştır.

Türkiye ve Kahramanmaraş bağ alanı arasındaki Korelasyon katsayısı $(r)=0,318)$ ve $B K\left(r^{2}\right)=0.101(\% 10,1)$. Türkiye için $\mathrm{DK}=\% 6,64$, Kahramanmaraş için ise $\mathrm{DK}=21,74$.

Çizelge 5. Türkiye ve Kahramanmaraş'ta 2004-2018 döneminde verim (kg/da).

Table 5. Yield of grape for Turkey and Kahramanmaras in 2004- 2018 (kg/da).

\begin{tabular}{|c|c|c|c|c|}
\hline \multirow{2}{*}{ Years } & \multicolumn{2}{|c|}{$\begin{array}{c}\text { Sofralı Çekirdekli } \\
\text { Table grapes with seeds }\end{array}$} & \multicolumn{2}{c|}{$\begin{array}{c}\text { Kurutmalı Cekirdekli } \\
\text { Raisin with seeds }\end{array}$} \\
\cline { 2 - 5 } & $\begin{array}{c}\text { Kahramanmaraş } \\
\text { Kahramanmaras }\end{array}$ & $\begin{array}{c}\text { Türkiye } \\
\text { Turkey }\end{array}$ & $\begin{array}{c}\text { Kahramanmaraş } \\
\text { Kahramanmaras }\end{array}$ & $\begin{array}{c}\text { Türkiye } \\
\text { Turkey }\end{array}$ \\
\hline 2004 & 403 & 566 & 560 & 467 \\
\hline 2005 & 468 & 597 & 565 & 551 \\
\hline 2006 & 439 & 580 & 677 & 529 \\
\hline 2007 & 340 & 621 & 131 & 473 \\
\hline 2008 & 686 & 615 & 1.163 & 619 \\
\hline 2009 & 753 & 707 & 1.369 & 627 \\
\hline 2010 & 944 & 723 & 868 & 670 \\
\hline 2011 & 703 & 720 & 937 & 632 \\
\hline 2012 & 731 & 713 & 935 & 681 \\
\hline 2013 & 560 & 718 & 1.049 & 620 \\
\hline 2014 & 545 & 688 & 1.034 & 689 \\
\hline 2015 & 727 & 570 & 1.225 & 650 \\
\hline 2016 & 390 & 667 & 373 & 796 \\
\hline 2017 & 543 & 754 & 569 & \\
\hline 2018 & 485 & 781 & 468 & \\
\hline
\end{tabular}

Kaynak: TUIK veri tabanından yararlanarak hazırlanmıştır (Anonim, 2019a).

Mevcut durumunu incelediğimiz Kahramanmaraş’ta bağcllı̆̆ın geliştirme potansiyelinin ne durumda olduğunun bilinmesi de önemlidir.

\section{Vejetasyon süresi}

Vejetasyon süresi Kahramanmaraş'ın yüksek rakımlı kuzey ilçelerinde daha kısa güney ilçelerinde ise daha uzundur. "Kahramanmaraş merkezde ilkbaharın son donları 01-10 Mart ve sonbaharın ilk donları ise 11-22
Aralık tarihleri arasında gerçekleştiği (Güvenç 2017) dikkate alındığında; 280 gün civarında bir vejetasyon süresi olduğu belirlenmiştir. Bir yerde bağcıllk yapılması için asgari vejetasyon süresi olarak 160 gün (sınır bir değer) olarak dikkate alınmaktadır (Oraman, 
1972). Vejetasyon süresinin 160 günden daha kısa olduğu yerlerde üzümlerin olgunlaş(a)madığı, kalite üzerine doğrudan etkisi bulunan; tat, aroma ve renk maddelerinin istenilen düzeyde oluş(a)madığ görülmektedir. Bu verilere göre Kahramanmaraş'ta vejetasyon süresi bağcılık için yeterlidir.

\section{Etkili Sicaklık Toplamı (EST)}

Sicaklık faktörü ile bir yerde ekonomik anlamda bağcılık yapmak imkanı arasındaki ilişki farklı yönlerden incelenebilir. Bir yerde bağcılık yapılması düşünüldügünde yıllık ortalama sıcaklık değerinin dikkate alınması gerekir. Bir bölgede ekonomik anlamda bağcılık yapılabilmesi için yıllık ortalama sıcaklığın $+9^{\circ} \mathrm{C}$ 'den aşağı düşmemesi gerekir (Yıldırım ve ark., 2005; Oraman 1970, 1972). Yıllık ortalama sıcaklık bakımdan Kahramanmaraş $16.9^{\circ} \mathrm{C}$ civarında bir sıcaklığa sahiptir (Çizelge 6). Buna göre yıllık ortalama sıcaklık değerlerini karşılamakta ve birçok üzüm çeşidinin yetiştiriciliğine uygun olmaktadır.
İlin aylık sıcaklık ortalamalarından yararlanılarak hesaplanan EST değeri 2.895 gün-derece olarak belirlenmiştir (Çizelge 6). Bağcılık yapılması planlanan bir yerde asgari olarak 900 gün-derece EST değeri istendiğinden (Yıldırım ve ark., 2005); Kahramanmaraş'a ait EST değeri (2.895 gün-derece) birçok üzüm çeşidinin gereksinimini karşılamaya yeterlidir.

\section{Güneşlenme süresi}

Kahramanmaraş'ın vejetasyon süresince güneşlenme süresi 2.144 saattir (Çizelge 6). Bağcılık için güneşlenme süresinin vejetasyon döneminde 1.300 saat olması istenir (Oraman 1970, 1972; Yıldırım ve ark., 2005). Güneşlenme süresini; bulutluluk, yöney (bakı) ve gündüz süresi etkilemektedir. Bitkinin güneşlenme ihtiyacının karşılanmaması meyve tutumu ve tanelerde şeker oranının düşük kalmasına neden olur (Okuroğlu ve ark., 1992; Karaçalı, 1993). $\mathrm{Bu}$ verilere göre ile ait güneşlenme süresi iyi bir bağcılık için yeterlidir.

Çizelge 6. Kahramanmaraş’ta aylık ortalama sıcaklık, EST değeri, güneşlenme süresi ve yağış.

Table 6. Average Temperature, EST value (effective temperature sum), sunshine duration and rainfall for Kahramanmaras

\begin{tabular}{|c|c|c|c|c|c|c|c|c|c|c|c|c|c|}
\hline $\mathrm{O}$ & Ş & $\mathrm{M}$ & $\mathrm{N}$ & $\mathrm{M}$ & $\mathrm{H}$ & $\mathrm{T}$ & A & $\mathrm{E}$ & $\mathrm{E}$ & $\mathrm{K}$ & A & Yilllk & \\
\hline \multicolumn{14}{|c|}{ Ortalama Sicaklık $\left({ }^{\circ} \mathrm{C}\right)$ Average Temperature } \\
\hline 4.9 & 6.5 & 10.7 & 15.5 & 20.3 & 25.2 & 28.4 & 28.5 & 25.2 & 19.1 & 11.7 & 6.7 & 16.9 & EST \\
\hline- & - & 0.7 & 5.5 & 10.3 & 15.2 & 18.4 & 18.5 & 15.2 & 9.1 & 1.7 & - & & \multirow{2}{*}{2.895} \\
\hline & & 22 & 165 & 319 & 456 & 570 & 574 & 456 & 282 & 51 & & & \\
\hline \multicolumn{14}{|c|}{ Güneşlenme Süresi (GS) (Saat) Sunshine duration (hours) } \\
\hline 3.3 & 4.0 & 5.4 & 6.7 & 8.0 & 10.0 & 10.5 & 9.8 & 8.7 & 6.5 & 4.5 & 3.2 & \multicolumn{2}{|c|}{ Toplam GS } \\
\hline & & 167 & 201 & 248 & 300 & 326 & 304 & 261 & 202 & 135 & & \multicolumn{2}{|c|}{2144 saat } \\
\hline \multicolumn{14}{|c|}{ 1) Rainfall ( $\mathrm{mm})$} \\
\hline 129.2 & 110.8 & 97.1 & 73.3 & 41.8 & 6.7 & 1.1 & 0.9 & 9.1 & 46.8 & 82.8 & 125.1 & \multicolumn{2}{|c|}{ Toplam 724.7} \\
\hline
\end{tabular}

EST: www.mgm.gov.tr veri tabanından yararlanarak hesaplanmıştır. Ölçüm Periyodu (1929 - 2017) (Anonim 2019b).

\section{Yağış}

Kahramanmaraş'ta yıllık ortalama yağış 724,7 mm'dir. Ancak vejetasyon döneminde 359,6 mm kadar yağış düşmektedir. Bir yerde bağcılık yapılırken 600 mm yağış varsa sulamaya gerek duyulmayacağ $;$; 300$600 \mathrm{~mm}$ arasında yağış varsa sulamanın bitki gelişmesi ve verime olumlu etki yapacağı ve yağış miktarı $300 \mathrm{~mm}$ ve altında ise mutlaka sulama gerektiği bildirilmiştir (Yıldırım ve ark., 2005). İlde yetiştirme periyodu ve yaz aylarının oldukça kurak geçtiği dikkate alındığında sulamaya belli ölçülerde yer verilmesi gerektiği görülmektedir. Ayrıca sonbaharın (Ekim ve Kasım) ilde yağışlı geçmesi geç hasat edilen kurutmalık çeşitlerde hasat sonrası işlemlerde sorun oluşturabilmektedir.

\section{SONUÇ ve ÖNERİLER}

Türkiye sofralık ve kurutmalık üzüm üretiminde Kahramanmaraş'ın önemli bir payı vardır. Kahramanmaraş'ta yetiştiriciliği yaygın yapılan kaliteli kurutmalı üzüm çeşitleri arasında Peygamber Üzümü (sinonim=Besni veya Pazarcık Üzümü) yer almaktadır. Pazarcık ilçesi Türkiye'nin en kaliteli kurutmalık Peygamber Üzümünün yetiştirildiği yerlerden biridir. Ayrıca İlde şıralık ve sofralık olarak Kabarcık; sofralık olarak Mahrabaşı üzümü yaygın yetiştirilmektedir. Bunların yanında Yıldız, Ağ üzüm, Yalova İncisi, Trakya İlkeren, Alphonse Lavalleé, Horoz Karası gibi birçok üzüm çeşidinin yetiştiriciliğine rastlamak da mümkündür.

İlimizde erkenci çeşitlerde hasat temmuz ayı başında başlamakta, geçci çeşitlerin hasadı ekim ayı ortalarına kadar devam etmektedir. Öte yandan ağustos ayının ortalarında da kurutmalık çekirdekli üzümlerin hasadına başlanmaktadır.

Kahramanmaraş'ta mevcut bağcılığın İlin sahip olduğu iklim şartları nedeniyle daha da geliştirilme potansiyeli vardır. Bu amaçla yukarda incelenen mevcut durum yanında, bağcılık sektörünün sorunları ve çözüm önerileri ile ilgili olarak daha önce yapılan 
çalışmalardan da (Anonim, 2017; Anonim, 2019d) yararlanarak aşağıdaki açıklamaları eklemek mümkündür.

Üreticilerin önemli sorunlarında bazıları şu şekildedir: Türkiye'nin en kaliteli çekirdekli kurutmalık üzümleri üretilmesine rağmen; pazarlama önemli bir sorundur. $\mathrm{Bu}$ sorunu, üzümün bir marka ismi ile paketlenmemesi artırmaktadır.

İkinci sırada ise gübreleme, hastalık ve zararlılarla mücadele gibi kültürel uygulamaların yeterince yapılmaması bulunmaktadır. $\mathrm{Bu}$ durum ürünlerin pazarlama sorunu ile ilişkilidir. Ayrıca artan girdi fiyatları kültürel işlemlerin yeterince yapılmamasına neden olmaktadir.

Son yıllarda bağlarda Bağ Küllemesi (Uncinula necator), Bağ Mildiyösü (Plasmopara viticola) ve Bağ Kanseri (Agrobacterium vitis) gibi hastallklarm yoğunluğunu artması üçüncü sırada yer almaktadır.

Yüksek terbiye sistemlerinin yaygın olmaması diğer bir sorundur. $\mathrm{Bu}$ durum verim düşüklüğü yanında mantari hastalıklar ile mücadeleyi de zorlaştırmaktadır.

$\mathrm{Bu}$ sorunların çözülmesi veya mevcut durumun iyileştirilmesi için aşağıda öneriler verilmiştir:

İlk olarak, üzüm üreticilerinin örgütlenmesi önem arz etmektedir. Pazarcık İlçesinde kurutmalık üzüm üreticileri Tarımsal Kalkınma Kooperatifi kurmuşlardır. Ürünün piyasaya arzında aracıların azaltılması üretici gelirlerini artıracaktır.

İkincisi, kooperatif üretim aşamasında yetiştiricilere katkı vermesi yanında markalaşma yönünde çaba sarf etmelidir.

Üçüncüsü, Tarım ve Orman Bakanlığı tarım havzasına göre Kahramanmaraş'ta desteklenen ürün listesine üzüm alınmalıdır.

Kahramanmaraş'ta üzümden pekmez, gün pekmezi, kuru üzüm, beyaz ve kara sucuk, samsa, pestil, kırma, çullama, ravanda gibi ürünler yapılmaktadır. Üzümden üretilen ürünlerin ambalajlanması hem pazarlama da olumlu katkı hem de katma değer kazandıracaktır. Bunların her birinden yeni bir marka çıkarmak mümkündür.

\section{Çıkar Çatışması Beyanı}

Makale yazarı herhangi bir çıkar çatışması olmadığını beyan eder.

\section{KAYNAKLAR}

Anonim 2013. Seçilmiş Göstergelerle Kahramanmaraş 2013. Türkiye İstatistik Kurumu (TUIK) Yayını, S: 166.
Anonim 2017. Kahramanmaraş Bağcılık Sektöründe Gelişmeler ve Fursatlar. Kahramanmaraş Valiliği (Basılmamış). KSÜ Pazarcık MYO, 23-24 Ağustos 2017.

Anonim 2019a. Bitkisel Üretim İstatistikleri. Türkiye İstatistik Kurumu (TUİK). http://www.tuik.gov.tr/ PreTablo.do?alt_id=1001. (Erişim Tarihi: 01.06.2019).

Anonim 2019b. İ ve İlçe İstatistikleri. https://www.mgm.gov.tr/veridegerlendirme/il-veilceler-istatistik.aspx?k=A\&m=K.MARAS. (Erişim Tarihi: 07.06.2019).

Anonim 2019c. Bitkisel Üretim İstatistikleri. Tarım ve Orman Bakanlığ 1 Bitkisel Üretim Genel Müdürlüğü (BUGEM), https://www.tarim.gov.tr/ BUGEM/Menu/9/Veriler.(ErişimTarihi:03.06.2019)

Anonim 2019d. Kahramanmaraş'ta Üzümde Rekolte Tahmin Raporu. T.C. Kahramanmaraş Valiliği İl Tarım ve Orman Bakanlığı Müdürlüğü, 19.08.2019.

Güvenç İ 2017. Sebzecilik: Temel Bilgiler, Muhafaza ve Yetiştiricilik. Nobel Yayınları, S: 288.

Karabat S 2018. Türkiye ve Dünya Bağcılığı. https://arastirma.tarimorman.gov.tr/manisa bagcilik/ Belgeler/genelbagcilik/DUNYA\%20VE\% 20TURKIYE\%20BAGCILIGI\%20SELCUK\%20KA RABAT.pdf. (Erişim Tarihi: 27.09.2018).

Karaçalı I 1993. Bahçe Ürünlerinin Muhafazası ve Pazara Hazırlanması. EÜ Ziraat Fakültesi Yayını No: 494, S: 444.

Okuroğlu M, Yağanoğu V Yardımcı N 1992. Meteroloji I. AÜ. Ziraat Fakültesi Yayını No: 125, S: 155.

Oraman NM 1970. Bağcıllk Tekniği II. AÜ Ziraat Fakültesi Yayınları NO:142, S: 283.

Oraman NM 1972. Bağcılık Tekniği II. AÜ Ziraat Fakültesi Yayınları NO: 470, S: 402.

Sabancı A 2009. Kahramanmaraş Koşullarında Sofralık Üzüm Çeşidi Adaptasyonu. Türkiye 7. Bağcıllk ve Teknolojileri Sempozyumu 5-9 Ekim, Manisa, Cilt II, S: 306-311.

Sütyemez M, Gündeşli MA 2004. Kahramanmaraş'ta İlinin Meyvecilik Durumu. I. Kahramanmaraş Sempozyumu, 6-8 Mayıs, Kahramanmaraş, S: 1247-1252.

Uzun İ 2015. Bağcılık El Kitabı. Hasad Yayıncılık, İstanbul, S.156.

Yıldırım F, Yıldız M, Kılınç NA 2005. Pratik Bağcılık. Manisa Tarım İl Müdürlüğü Yayını, Ege Form Ofset Basım, Manisa S: 208.

Yinanç R, Elibüyük M 1988. Maraş Tahrir Defteri. Osmanlı Tarihi Araştırma ve Uygulama Merkezi Yayınları No: 1, S: 468.

Yüzer AF, Ağaoğlu E, Tatlıdil H, Özmen A, Şıklar E 2006. İstatistik. Anadolu Üniversitesi Yayını, No: 1448, S: 331. 